\title{
Creating an Online Self: Developing Virtual Identity in Online Group Interaction Spaces
}

\author{
George N. King'ara ${ }^{1}$, Deckillah S. Omukoba ${ }^{2}$ \\ ${ }^{1}$ Lecturer, Kenyatta University, Kenya \\ ${ }^{2}$ Kenyatta University, Kenya
}

\section{ABSTRACT}

Online groups have pervasively become platforms for association and interaction. Hence, it is important to study how interactions on these virtual groups affect the selves of individual group members, and whether communication activities in these groups lead to formation of virtual identities of active members which is distinguishable from their non-mediated identity. To analyze the development of virtual identity, four focus group discussions of ten youthful participants each, who were members of various online groups, were conducted and eight social media experts were interviewed. Concepts of Communication Theory of Identity (CTI) and Uses and Gratification Theory were employed to analyze collected data in assessing how online group interactions that involve fashioning identity, impression management, anonymity and pro-social behavior lead to formation of online group members virtual identity. We first interrogate how these online groups shape behavior online by interrogating the individual group member's conversations and actions online and paralleling them with their conversations and actions offline. Second, using the threedimensional identity formation model (Crocetti, Rubini, \& Meeus, 2008), we crystalize how these online interactions and behavior cause individual group member's to feel, think and understand themselves in ways that promote a unique online-self, which we refer to as the virtual identity.

Key Words: Virtual Identity, Fashioning Identity, Anonymity, Online-Self

DOI 10.35942/ ijcab.v5i3.185

Cite this Article:

King'ara, G., \& Omukoba, D. (2021). Creating an Online Self: Developing Virtual Identity in Online Group Interaction Spaces. International Journal of Current Aspects, 5(3), 18-31. https://doi.org/10.35942/ijcab.v5i3.185

\subsection{Introduction}

According to social identity theory (Hogg, 1996) people form a social identity of values, attitudes and behavioral intentions from the perceived membership in distinct self inclusive real or imagined social groups. An individual's self-identity typically results from the membership in a pre-existing self inclusive social group, including vocation (Hogg \& Terry, 2000) and avocation (Underwood, Bond \& Baer, 2001). These motivations for joining traditional, face to face groups can be extended to membership in online groups. One of the foundational issues in establishing a sense of virtual identity has to do with the degree to which people feel they are able to experience a connection to others through technology. The human perception is extremely important in establishing this connection. According to Kang et al (2019), the sense of "being there" that many report experiencing while engaged in the online realities communicated through cyberspace can be explained in terms of telepresence. Telepresence essentially points to the extent to which one feels present in the mediated environment, rather than in the immediate physical environment. This sense of 'being there' is enhanced by the quality of vividness, which refers to the amount of sensory information the medium makes available to a person. For example, applications like Facebook, 
Whatsapp, Twitter, YouTube and Instagram allow for the sharing of pictures, videos, emojis, voice recording and other related features like filters, locations that create a collection of senses engaged and the extents to which any one of those senses is stimulated. This creates a sense of realism, and this same sense is enhanced by the degree of interactivity the medium affords to people. Identity therefore deals with the question of 'who am i' which usually refers to further questions of belonging and of locating oneself in social contexts (Carroll, Jiang \& Zhang, 2010).

An identity is a complex personal and social construct, consisting in part of who we think ourselves to be, how we wish others to perceive us, and how they actually perceive us, (Ackerman, 2019). Crocetti, Rubini, and Meeus (2008) proposed and advanced a three-dimensional identity model which focused on the dynamics by which adolescents form, evaluate, and revise their identities over time. The model was used to study how adolescents in Italy and Netherlands developed identity while at school (the social domain) because this is where they spend most of their time and interact with their schoolmates (interpersonal domain). The three-dimensional model (Crocetti, Rubini, \& Meeus, 2008) posits three dimensions as under-lying identity formation. These include: Commitment, In-depth exploration and Reconsideration of commitment. Commitment involves enduring choices that the adolescents make in various developmental domains and the self-confidence they derive from these choices. In-depth exploration refers to the extent to which they explore actively their commitments, reflect on them, and discuss their choices with other people. Reconsideration of commitment includes the comparison of present commitments with alternative commitments because the current ones are no longer fulfilling. This model was deemed fit in studying how the youth develop a virtual identity in online groups (the social domain) in the process of online interaction (interpersonal domain), bearing in mind that the youth spend a considerable amount of time online.

As a new phenomenon, online communities are yet to be fully researched for their ability to foster community members' identities, or the character(s) of such identities for the members of online communities. Given the fact that the nature of online communities members' interaction is virtual, questions abound on the nature of identities formed during interactions by members of online communities (groups) as they also come from disparate socio-cultural physical communities. Previous research done on online communities has barely scratched the ground of online communities in Africa, yet it has been established that proliferation of online group membership in Africa, particularly in Kenya, is growing. It is therefore important for researchers in the field of communication to understand the reach of this online interaction by members of existing online social groups, the characteristics of the groups Internet users join, and the reasons they join such groups. This articles seeks to establish how online group membership can develop virtual identities in the youth who interact in online groups; identities that are separate from their non-mediated ones.

\subsection{Theoretical Framework}

Two theories are adopted to support our quest of exploring how interaction by members of online groups can lead to the formation of virtual identities of individual active members of the groups. The Communication Theory of Identity (CTI) explains how identity is constitued and how it is founded in community members' interactions (communication). The Uses and Gratification Theory (U\&G) explains how media choices human beings make for communication is the precursor to the nature of the outcome of community members' interactions, one of which is whom they become due to the experience of that interaction. 
International Journal of Current Aspects, Volume 5, Issue 3, July 2021, PP 18-31, ISSN 2616-6976

[iJCAB

\subsection{The Communication Theory of Identity (CTI)}

The Communication Theory of Identity (CTI) was developed by communication scholar Michael Hecht in 1993. The theory was developed based on theory and empirical data suggesting that communication is an element rather than just a product of identity. The communication theory of identity expands the notion of identity to view it as layered (Faulkner \& Hecht, 2007). From this theorizing emerged CTI's definition of identity as the multilayered ways that individuals and communities socially construct themselves. Seeking to view identity as more processual and multilayered, Communication Theory of Identity presents a more comprehensive or synthetic view of identity integrating community, communication, social relationships, and self-concepts, while locating identity in all these layers.

The basic overarching propositions that define identity are: Identities have individual, social, and communal properties. Identities are both enduring and changing. Identities are affective, cognitive, behavioral, and spiritual. Identities have both content and relationship levels of interpretation. Identities involve both subjective and ascribed meaning. Identities are codes that are expressed in conversations and define membership in communities. Identities have semantic properties that are expressed in core symbols, meanings, and labels. Identities prescribe modes of appropriate and effective communication. Identities are a source of expectations and motivations. Identities are emergent; they are obtained when we enter into relations with others who have identities. This layered perspective views one's identity formation and management as an ongoing process of communication with the self and with others rather than as a simple product of communication or basis for producing communication (Hope et al, 2019).

The theory posits that individuals internalize social interactions, relationships, and a sense of self into identities through communication. As online group members communicate online they develop a sense of their self-online and this self is what they manage and express and it becomes their virtual identity. In turn, identity is expressed or enacted through communication. In other words, the relationship between communication and identity is reciprocal; the way one communicates online forms their identity there, and the identity formed there determines how one communicates. From this perspective, communication helps build, sustain, and modify one's identity. The theory was found fit for studying identity formation via online interactions group members, since it articulates this reciprocal relationship which enables the development of a unique identity for the members online. This theory was applied in data collection particularly in the designing of focus group discussion questions geared to finding out how the youth communicate online as opposed to how they communicated offline. Each participant's viewpoint was analyzed as a trend or generalization of their identity online. The responses given were analyzed according to what meaning and pattern they contribute to the virtual identity of the youth.

\subsection{The Uses and Gratification Theory (U\&G)}

The Uses and Gratification Theory (Katz, Blumler \& Gurevitch, 1974) has its foundation in communication research, originally focusing on motivations for choice of mass media and mass communication (Ling \& Pedersen 2003). Reiss et al. (2021) maintain that to focus fully on the social and cultural impacts of new communication technologies may be premature until we have grasped exactly how and why people are making use of these media channels. This approach focuses on the consumer- the audience member rather than the message. The theory visualizes the audience member to be a discriminating user of media. The audience is assumed to be active and goal directed. The audiences are largely responsible for choosing media to meet their own needs. 
The media are considered to be only one factor contributing to how needs get met, and the audience members are assumed to have considerable agency or in essence know their need and how to gratify those needs. The underlying assumption is that audiences are active and they seek out that content which provides the most gratification (Fawkes \& Gregory, 2001). Fawkes and Gregory (2001) further added that "the level of gratification depends on the level of need or interest of the individual". Katz et al. (1974) added that the U\&G approach is concerned with: "(a) the social and psychological origins of, (b) needs, which generate, (c) expectations of, (d) the mass media or other sources, which lead to, (e) different patterns of media exposure (or engagement in other activities), resulting in, (f) need gratifications and, (g) other consequences, perhaps mostly unintended ones". This model informed the present study in the sense that, (a) the participants have social and psychological needs, which (b) determine the Gratifications Sought (GS) through specific online groups and (c) have expectations of the different online groups available, which (d) influences them to access these online groups, (e) and engage in different online activities, resulting in (f) gratifications obtained (GO) and, (g) other consequences (both positive and negative), mostly unintended, gained through the interactions with members of the online groups they joined.

\subsection{Methodology}

This article is based on a study that sought to establish the level of proliferation of online group membership by the youth in Nairobi County, Kenya, the reasons that motivate them to join such groups and whether online group membership develops in the youth a virtual identity that is separate from their non-mediated identity. A qualitative research approach was used to collect and analyse data. Primarily, a group of forty youth were placed in four different focus groups and had conversations around their behaviour online as a way of understanding what they do there, with regards to their actions, texts, audio and visual presentations and to what extent that behaviour reflects who they are online and who they want others to know them as there. Interviews were conducted with eight social media experts, who specialize in online content development, and communication research. This group was deemed more suitable since its members have a greater understanding of the online space, the interactions that happen there as well as the behavioral dynamics and psychology associated with online interactions.

\subsection{Research Findings and Discussions}

The data analysis sought to examine whether the youth - who are members of online groups develop a unique identity online, referred to as the virtual identity. Crocetti, Rubini, \& Meeus's, (2008) three dimensional identity model which includes: Commitment, In-depth exploration and Reconsideration of commitment was used in analyzing data for this objective. The researcher examined the respondents' commitment to a particular self-presentation online. Commitment here refers to enacting enduring choices with regard to the social domain (the online group/s) and the self-confidence and gratification respondents' derive from these choices. This was achieved by examining how the online group has influenced the way they present themselves online as opposed to offline. The researcher also examined the respondents' in-depth exploration which represents the extent to which they think actively about the commitment to the self they present online. How they seek for additional information with regards to their commitment as well as how they talk about their commitment to the self they present online. This was achieved by asking the question, 'how do you want others to perceive you online'? The researcher also examined the respondents' reconsideration of commitment which refers to the comparison of present commitments to a self- 
International Journal of Current Aspects, Volume 5, Issue 3, July 2021, PP 18-31, ISSN 2616-6976

iJCAB

presentation with possible alternatives because the current commitments are no longer satisfactory. Reconsideration of commitment combines loosening existing commitments with broad exploration of new possibilities. This was done by examining how other peoples' presentation online affected their self-presentation online. This was analyzed to find out whether existing commitments to a self-presentation online were secured during a process of reconsideration. Or if during the reconsideration process, one's present commitments are deemed to be inadequate and are discarded in favor of new commitments. The findings based on the Crocetti, et al.'s (2008) three dimensional identity model are discussed below as follows:

\subsection{Social Media Shaping Behaviour Online}

The participants' response to the question, 'how has the online group influenced the way you present yourself online as opposed to offline?' was as follows

Participant 23/2019 observed:

I am very cautious online, I am very careful not to say things that can be controversial or cause me a lot of backlash. I tend to play safe online than offline. I show my best behaviour online, like I talk of clean ups, the work I do with the children's home, academic related stuff, as well as the service I do at my local church.

Participant 24/2019 argued:

Because many people tend to bash, troll and criticize others online, I do the same too albeit on my anonymous page. I troll a lot in the online groups that am a part of. It has just become a behaviour that I have developed online. I get to say what I want with no chills! I definitely don't talk like that offline

Participant 25/2019 said:

I am just a different person online as opposed to offline; online my behaviour is different to the extent of being controversial. I guess it's because of the pressure that exists in the online space. There can be a lot of bullying as well as competition, making it hard to just be normal online; you need to put up an image that is A-game online.

Participant 26/2019 said:

I use a lot of filters in my online pictures; the jewelry, hat, the complexion and makeup on my online profile picture is all filters! It makes me look perfect, that is definitely not how I look like in real life or offline, but I like posting those perfect pictures online, because the filters are available and I use them to look perfect! I receive a lot of good comments and likes with those pictures and it boosts my self-esteem. This makes me use more filters while posting my pictures.

Participant 27/2019 reported:

For a long time I have posted pictures of a flashy lifestyle like a lot of money and luxurious cars, because I want to be associated with the identity of wealth and fame even though I am not there yet in real life. Offline am just broke!

In an interview with Social Media Expert 7 he argued that:

The information shared on social media may be persuasive and as a result it may alter the behaviour of the person. It gives them a platform to exercise behaviour; it puts 
International Journal of Current Aspects, Volume 5, Issue 3, July 2021, PP 18-31, ISSN 2616-6976

iJCAB

pressure on them that makes certain behaviours to show, and that behaviour becomes what they are identified with, it ultimately becomes their identity. That is why we have names such as slay queens or online influencer. These people have developed a certain identity online that they are known for.

The above findings reveal that the youth make choices of how they want to be known online. They are seen to be committed to a particular self-presentation online that can be totally different from who they are offline. They practice these choices of self-presentation and derive gratification as a result. A good example is participant 23/2019 who enacts the choice of being cautious online. The participants reveals that she is careful of the things she says online and engages in playing safe online as well as showing her best side through pro-social behaviours such as cleaning, volunteering at the children's home and showing the service she gives at her local church. Participant 24/2019 has made a choice to be anonymous and as a result he practices trolling. The participant is gratified when he says what he wants to say online, what he refers to as 'no chills'. Participant 25/2019 practices being controversial and putting up an A-game while participant $26 / 2019$ chooses to use filters while posting her pictures online. This participant feels confident when she receives many likes and positive comments, as this reinforces her choice to use more and more filters online. Participant 27/2019 enacts a flashy lifestyle and feels confident when he is identified with wealth and fame. These responses concur with the fact that the youth are committed to a particular virtual identity through the choices they make and the gratification they gain from those choices. At this stage the participants are seen to be making a relatively firm choice about a virtual identity and engaging in significant activities geared towards the implementation of that choice.

\subsection{Perception Online}

In this next step, the researcher examined the respondents' in-depth exploration by assessing how they actively think about their commitment to the self they present online, and how they seek additional information with regards to their commitment to a virtual identity. As well as how they talk about their commitment to this virtual identity. This analysis was done by examining the question, 'how do you want others to perceive you online?' Perception was employed to investigate how the senses are used to create the online world that the youth live in. Perception is very powerful, because it tricks the brain into believing, thus one's online presentation becomes a representation of who they are perceived by others to be (Prestidge, 2018).

Participant 28/2019 explained:

I want to be perceived a certain way online, I want to be liked, admired and celebrated, but when people say things that are contrary or negative, or when they don't say anything at all, like liking my photos and commenting on them, it makes me feel less valuable, stressed and my self-esteem goes down, so I tend to take pictures that makes me popular, such as dressing hot and standing next to pools. In fact what I portray on my Instagram for example is absolutely opposite of my true self that I don't allow people who really know me offline or criticize my Instagram life to view my Instagram page, because it's so not a true representation of me in the real world. I have even had arguments with and blocked people who criticize my Instagram life.

Participant 29/2019 said: 
International Journal of Current Aspects, Volume 5, Issue 3, July 2021, PP 18-31, ISSN 2616-6976

iJCAB

I want to be perceived as affluent. I am totally different online than I am in real life. In real life I live at kwa Kairo but I cannot post pictures of that place, I always post pictures in nice neighbourhoods. I can never post pictures of where I live in real life. These flashy life postings receive a lot of likes and comments and that makes me feel good! That's how I want to be known online!

Participant 30/2019 reported:

I always post pictures standing next to expensive cars like Range Rovers, and in nice places. So I always find these nice cars and nice places and take pictures next to them. My online friends believe I am doing well and my life is all rosy, I like that identity, and the comments that come with it! But the truth of the matter is, 'kwa ground vitu ni different!'

In an interview with Social Media Expert 7, he explained that:

It's all about accommodation: the youth want to fit within the social media realities; they want to be admired, to engage with people who have the same values and belief systems. So they will accommodate what is there, by copying or enhancing; and therefore their identity changes over time, or rather their identity online changes from their identity offline. Meaning that overtime they develop an online identity or a virtual identity.

In an interview with Social Media Expert 8, she argued that:

There are lots of apps that help the youth achieve these kinds of manipulation of identity, like face apps. They can edit their photos; they can edit out people they don't want. A man can put the photo of a woman; they can edit locations and even write that they are at a particular location when they are not. They also post specific places they have visited like hotels, beaches and suites but not the other places that make up their lives, like the estates they live in, or their home in the village. There are some who remain anonymous. There is also synonymity; where half of what is said is true while the other is not. Since Social media is anonymous and remote it gives them a lot of way and play to manipulate their identity.

In an interview with Social Media Expert 3, she said:

Online the youth present a character that is attractive for the public to see, but offline they go back to their own individuality or individual identity. The concept of virtual identity comes to play where they fit in online but when they go offline they embody their ethnic, cultural, values that add up to who they are. This is majorly because; online they are influenced by media, international pop culture, peers, celebrities and the like.

In an interview with Social Media Expert 2, he said:

Online they put their best moments carefully edited and crafted because of peer pressure, to gain followers, and have a voice. Some of them have so many friends online but in real life they are lonely and confused. They are not sure of themselves offline, neither are they go-getters as they portray online they are actually laid back. But there are also some youth who are ok enough to present the same self-offline and online.

Commitment and In-depth exploration are intertwined processes of identity development. Actively committed participants are seen to continue to intensively explore the domains of their choices in 
International Journal of Current Aspects, Volume 5, Issue 3, July 2021, PP 18-31, ISSN 2616-6976

[IJCAB

the commitment stage. For example, Participant 28/2019 says, 'I want to be perceived a certain way online'. It means that the participant actively thinks about the kind of way she wants to be perceived online. She is aware of the kind of identity she wants to develop online. The participant goes ahead to reveal how she wants to be perceived by using words such as: liked, celebrated and admired. The participant also actively thinks of the negative or contrary things that people may say or even if they don't say anything at all. The participant spends time thinking about her pictures being liked and given positive comments. This is gratifying to her because it boosts her self-esteem and makes her feel valuable. The participant therefore posts pictures that will make her popular and even argues and blocks people who criticize her online presentation. This means that she works hard at developing that virtual identity. It is an active process as opposed to being passive.

Participant 29/2019 actively thinks of affluence. The participant is aware of the virtual identity he wants to develop. In fact he says that he can never post pictures of kwa-Kairo which is where he lives in reality. This means that the participant blocks out anything that may negate the virtual identity he is developing online whether or not that thing is part of his offline identity. The participant looks out for high end neighbourhoods and presents images of such places as a representation of where he lives. Meaning that he finds the materials that will help him 'construct' the virtual identity he wants. The participant thinks of getting many likes and positive comments online, this is what gives him gratification and affirms the virtual identity he has developed online. The participant also talks of how he wants to be known online and that is affluent. It means that he embraces this virtual identity that he has developed online. Participant 30/2019 thinks of expensive cars like Range Rover. She likes it when others believe that she is doing well. As a result she seeks out more nice cars and locations and takes pictures and posts them online. The participant talks about liking an identity of doing well even though 'kwa ground vitu ni different'.

In-depth exploration can therefore be conceived as an adaptive identity process, because it implies that the participants deal with existing commitments in an active way. These participants work hard to maintain their commitment to a virtual identity, so that they can continue to receive more and more likes as well as positive comments. This is what gives the gratification and affirms their commitment to a virtual identity. In the event that they don't receive as many likes or as many positive comments then they work on improving or fashioning that virtual identity more so that it can fetch the gratification that they are looking for online. Further examples below reveal the same:

Participant 31/2019 on the focus group discussion said:

I want others to perceive me as smart, knowledgeable, exposed, a go-getter, and a leader. I also want to be perceived as successful, so I post highlights of the nice places I have visited physically.

Participant 32/2019 said:

I want others to perceive me as an expert in photography. I love taking pictures and have started my own photography business, so I want to be perceived as a great photographer with much experience, breath taking shots and a happy clientele.

Participant 33/2019 reported:

I want to be perceived as very successful, very happy and very friendly. I want to be seen as someone who is living their dream. So I post picture of things I like especially shoes with hash tags like \#mynewestbae to give the impression that I own many of these kinds 
International Journal of Current Aspects, Volume 5, Issue 3, July 2021, PP 18-31, ISSN 2616-6976

iJCAB

of expensive things. I also post videos on Instagram and go live on Facebook especially when am having fun like in parties or am hanging out at a nice place.

Participant 34/2019 said:

I want to be perceived as a good example to others. I want others to perceive me as real and not fake. So I tend to put my real self-online.

Participant 35/2019 said:

I am more perfect online in terms of my pictures than I am offline. I present a more intelligent self -online than I am offline. Online I post intelligent quotes from famous people or books, but offline I never talk like that. I also present a more confident selfonline than I am offline, so there is a very clear distinction of me online and me offline. My friends sometimes make fun of me but I don't care that's my online vibe!

Participant 36/2019 in the focus group discussion explained:

The pictures I post online are not a true representation of who I am offline there is a particular image of me that I prefer online. I care much about what people say about me online, so I try to look really great

In an interview with Social Media Expert 8, she argued:

The youth want to be perceived positively: they want to create an identity that is pleasing to people, they want to be admired. They want to be reassured; there is a lot of attention seeking online and they want their identity enhanced by the way people see and view them on these online platforms. To achieve this they go a long way including creating a self-online that is totally different than the self-offline.

The youth thus put a lot of work with in-depth exploration of their self-online, because they are committed to the identity that they are developing there. Participant 31/2019 for example reveals that they want others to perceive them as: smart, successful, knowledgeable, and exposed, a gogetter and a leader. As a result the participant posts pictures of nice places they have visited physically so that they can reinforce that virtual identity.

Participant 32/2019 wants to be known as an expert in photography. As a result he advertises his photography business online, showing breath-taking shots as well as talking about his happy clientele.

Participant 33/2019 actively thinks about herself as being successful, very happy and friendly and living her dream. This is the virtual identity she is committed to and wants to be perceived as. The participant posts pictures of expensive shoes to give an impression that she owns very expensive things. She also posts videos of herself while having fun at parties or visiting nice places.

These responses corroborate with Anderson \& Jiang (2018) who said that in online spaces, fashioning identity is very prevalent, because the youth want to impress. Social media or any media is connected with an audience, whether known or unknown, and the participants on these platforms are always aware that they are being 'watched', which makes them want to be seen in a particular way. They feel that they are responsible for how their audience see them. They engage actively in building that image that they want their audience to see, and if the image they have built is favaroable then they spend time maintaining it or improving on it and talking about it so that they can continue to be celebrated by their audience. It is therefore a performance of sorts since the 
International Journal of Current Aspects, Volume 5, Issue 3, July 2021, PP 18-31, ISSN 2616-6976

iJCAB

participants are always conscious of the fact that they are being watched and ultimately someone will give feedback of what they have seen. Whether that feedback is loud or silent still matters to them. Negative consequences could also stem from in-depth exploration. For example, one can become overly involved in evaluating and contemplating their current commitments, becoming unsure and sceptical about their choices such as participant 28/2019 who feels less valuable, stressed and experiences low self-esteem as a results of overly evaluating her self-presentation online.

\subsection{Influence of Other Peoples' Online Presentation}

With the prevalence of social media, Stein (2019) argues that the practice of compare and despair has become excessive. The question is: are we judging ourselves too strictly against the filtered images of our "friends?" Stein says that:

We may consciously, or subconsciously, internalize a post about a peer's wedding as: Mary got married. Everyone is getting married. I am never going to meet anyone. What is wrong with me? I should try to go out and meet people. Let's go to the bar! (Stein, 2019).

The question, 'how does other peoples' presentation online affect your self-presentation online?' therefore sought to understand in what ways are perceived shortcomings influencing the youth to reconsider their commitment to their virtual identity. Reconsideration of commitment refers to the comparison of their virtual identity with possible alternatives because it is no longer satisfactory. It examined the loosening of existing commitments with broad exploration of new possibilities thus constructing and revising identity over time. The responses were analysed to find out whether existing commitments to a virtual identity were secured during a process of reconsideration. Or if during the reconsideration process, one's present commitment to a virtual identity were deemed to be inadequate and were discarded in favour of new a new virtual identity.

Participant 37/2019 in the focus group discussion argued:

When someone is where I want to be professionally, physically or relationally, I tend to mirror what they do. If their values agree with mine they influence me to alter my presentation. If they are my role model they alter my presentation online, but if not their opinions and behaviour online doesn't affect mine.

\section{Participant 38/2019}

Yes how other people present themselves online affects my presentation. There are many people I want to be like. I admire their looks, their many followers. How they dress or the things they post online. So I try to be like them even though it's not easy because you need to have a lot to get there; like have that stuff and that following they have. So it's kind of stressful to keep up online.

Participant 39/2019 in the focus group discussion said:

Yes, it does because I have role models and I emulate the way they present themselves online. I try to fit in with how they present themselves online. I consider myself to be a very religious person therefore I follow people online who preach what I believe. Their messages inspire me and challenge me to be a better person. I also repost their messages as a way of encouraging others to follow these values that continue to change and shape me every day. 
International Journal of Current Aspects, Volume 5, Issue 3, July 2021, PP 18-31, ISSN 2616-6976

[IJCAB

Participant 40/2019 in the focus group discussion argued:

Yes, both negative and positive; when I was on Instagram it shook my self-esteem a lot because I wanted to be like the people I saw online but I did not have the means to keep up with them, so I exited and took a break because I felt like I could go insane. The online world can really put you down when you don't have the proper guideline; it depends with the people you associate with online, if they have a positive vibe that's great, but if they are all about show off, you can suffer trying to keep up with them.

In an interview with Social Media Expert 1, she argued:

The youth are subject to opinion, they are easily influenced. Most youth feel the pressure of being like others or the many influencers out there like Akothee, Vera Sidika or Diamond who have a large following and they influence the behavior of the youth. Yes there are some who are sure of themselves and are confident but most youth are swayed by other people online.

In an interview with Social Media Expert 4, he said:

The youth have their own perceptions, they are very critical of what others present online, so they only take/ borrow what relates to them and what they disagree with or it doesn't add value to them they reject by creating their own alternative views and perceptions about the issue or context being presented.

In an interview with Social Media Expert 1, she argued:

They do a lot especially presentations by celebrities and their mentors. People like Diamond, Akothee, and the like have a lot of influence on the youth and when they post something online they shape the presentation of the youth as the youth mimic what they say or do online. The language and image of these influencers empowers the youth to present themselves a certain way online. It was out of such presentations online that we saw the rise of sponsors, socialites and slay queens and a number of youth doing bizarre things online like posing half naked to look like these celebrities and acquire the status and following that they have. It's an issue of identity crisis online.

Reconsideration of commitment encompasses the investigation of possible new commitments. It focuses on one's attempt to change their current commitment because they are no longer satisfied with their choices. It starts with a participant's evaluation of their present commitment. The youth are influenced a lot by others online; they constantly reconsider their self-presentation online based on what others are presenting there. The people who contribute to this reconsideration process include celebrities, social media influencers or their peers who set the agenda and control the narrative on these online groups. As a result, the youth find themselves aping their behaviour, adopting their actions and endorsing their culture. Before long they assimilate to their way of life and feel very confident being that way and as a result develop that as their virtual identity. This stage captures the iterative process of constructing and revising one's virtual identity. A good example is participant $37 / 2019$ who says that he mirrors what other people do online meaning that he engages in the process of comparison with possible alternatives. In his case, it is people who seem to have some level of success professionally, physically or relationally. He says that if their values agree with his then he mirrors them and if they don't then he doesn't care for them. This means that in the process of reconsideration the participant's existing commitments remain secure. Participant 38/2019 says that she looks at peoples' looks, dressing, the things they have posted and 
International Journal of Current Aspects, Volume 5, Issue 3, July 2021, PP 18-31, ISSN 2616-6976

[IJCAB

the following they have. This is what influences how she then presents herself online. It means that the participant compares her commitment with possible alternatives, because she feels that her current commitments are no longer satisfactory. The participant says 'I try to be like them' meaning that she deems her own presentation to be inadequate and therefore it is discarded in the process of reconsideration. This is also seen in participant 39/2019 whose possible alternatives are role models. The participant considers himself to be very religious and therefore in the process of reconsideration of commitment with the role models his own commitment to a religious virtual identity is secure. Participant 40/2019 says that when she compared herself with others on Instagram it shook her self-esteem. This means that in the process of reconsideration her commitment to her virtual identity was deemed inadequate. The participant says that she wants to be like the people she sees on Instagram. This means that she discarded her own virtual identity, in favour of other alternatives. Because the participant was not able to match up with other peoples' virtual identity she exited the online space. This means that she felt that she was too inadequate to develop that identity online and could not settle for her previous commitment to a virtual identity. The participant had the option of suffering trying to keep up or just quitting the online space, and because she could not keep up she chose to exit the online space.

The process of reconsideration of one's online presentation is a constant challenge for the youth. Most of the youth will go out of their way to look like their peers, celebrities or social media influencers. Many of their YouTube channels, Instagram pages, and WhatsApp or Facebook groups mirror the discussions and mannerisms of these social influencers. This is in line with the Communication theory of Identity (CTI) which builds from the interactionism tenet that suggests that identities are emergent and obtained when people enter into relations with others who have identities as well (Hope et al, 2019).

This behavioural mimicry also includes verbal, goal, and emotional contagion and attitudinal convergence. The messages on these platforms are also designed to target the youth in areas of marketing with the idea to influence them to follow, or buy a product or alter behaviour, and before long they embody the identity crafted by the persuasive messages. One of the most persuasive message at the time of this study was 'my dress my choice' by Akothee, a social media influencer. This consequently became the message and style embodied by many youth online.

It is also important to appreciate the fact that the youth can likewise weigh what is going on online against their own values and standards during this process of reconsideration of commitment; if the messages online do not mirror their commitment, values and way of life then they reject them. Hoewever, if they do they easily embrace them, because to some extent they seek to advance and affirm the virtual identity they have developed as stated by participant 39/2019 who embraces values that agree with his own and rejects those that are contrary. This means that in the process of reconsideration his commitments are secure. The participant believes that his identity has been shaped by these commitments and as a result he is convinced that the same values and conversations are powerful enough to change others online who come in contact with them, thus it informs his efforts to spread the news online. This is in line with the Communication Theory of Identity (CTI) which builds from the interactionism tenet that suggests that identities have individual, social, and communal properties. They are both enduring and changing. Identities are affective, cognitive, behavioral and spiritual. Identities have both content and relationship levels of interpretation (Hope et al., 2019).

\subsection{Conclusions}


International Journal of Current Aspects, Volume 5, Issue 3, July 2021, PP 18-31, ISSN 2616-6976

[IJCAB

As we examine the behaviours of youth online, we understand what they do there with regards to their actions, texts, audio and visual presentations and to what extent that behaviour reflects who they are online and who they want others to know them as there. The youth are intentional in developing a particular identity online whether that presentation is similar or contary to their offline selves is up to them to decide. But whatever self they developed is a self they maintain and are loyal to. However, manipulating their identity is nothing new, even in online communications, fashioning identity is still a perennial concern of them. The need to perform online is very real. Since online group members are always aware that they are before an audience, they automatically shift into role play because of the heightened level of surveillance online, leading to the formation of a particular self online. The youth commit to these self presentations online, engage in in-depth exploration of these commitments and also reconsider their commitments online, forming a unique identity there referred to as one's virtual identity.

\section{Reference}

Ackerman, C.E. (2020). What is Self-Concept Theory? Retrieved from: https://positivepsychology.com/self-concept/ on 30.03.2020

Anderson, M. \& Jiang, J. (2018). Teens' Social Media Habits and Experiences. Retrieved on 12.3.2020 from: https://www.pewresearch.org/internet/2018/11/28/teens-social-mediahabits-and-experiences.

Carroll, J. Jiang, H. \& Zhang, S. (2010). Social Identity in Facebook Community life: International Journal of Online Communities and Social Networking. 2(4), 66-78.

Crocetti, E., Rubini, M., \& Meeus, W. (2008). Capturing the dynamics of identity formation in various ethnic groups: Development and validation of a three-dimensional model. Journal of Adolescence, 31, 207-222. doi: 10.1010/j.adolescence.2007.09.002

Faulkner, S. L., \& Hecht, M. L. (2007). Tides in The Ocean: A Layered Approach To Culture and Communication. In B. B. Whaley \& W. Samter (Eds.), Explaining Communication: Contemporary Theories And Exemplars (pp. 393-402). Mahwah, NJ: Lawrence Erlbaum

Fawkes, J., \& Gregory, A. (2001). Applying communication theories to the Internet. Journal of Communication Management, 5(2), 109-124.

Hecht, M. L. (1993). A research odyssey: Towards the Development of a Communication Theory Of Identity. Communication Monographs, 60, 76-82.

Hogg, M. A. (1996). Group structure and social identity. In W. P.Robinson(Ed.), Social groups and identities: Developing the legacy of Henri Tajfel (pp. 65-94). UK: Butterworth Heinemann.

Hogg, M. A., \& Terry, D. J. (2000). Social identity and self-categorization processes in organizational contexts. The Academy of Management Review, 25(1), 121-140.

Hope, E. C., Gugwor, R., Riddick, K. N., \& Pender, K. N. (2019). Engaged against the machine: institutional and cultural racial discrimination and racial identity as predictors of activism 
International Journal of Current Aspects, Volume 5, Issue 3, July 2021, PP 18-31, ISSN 2616-6976

iJCAB

orientation among Black youth. American journal of community psychology, 63(1-2), 6172.

Kang, S., O’Brien, E., Villarreal, A., Lee, W., \& Mahood, C. (2019). Immersive Journalism and

Telepresence: Does virtual reality news use affect news credibility?. Digital journalism, 7(2), 294-313.

Katz, E., Jay, Blumler, J.G \& Gurevitch, M (1974) "Uses and Gratifications Research."The

Public Opinion Quarterly 4. 3738.

Ling, R., \& Pedersen, E. (2003). Modifying adoption research for mobile internet service

adoption: Cross-disciplinary interactions. In: Proceeding of the 36th Hawaii International Conference on System Sciences. Hawaii: The Computer Society.

Prestidge, B. (2018). The power of online perception.

https://www.entrepreneur.com/article/309922

Reis, L., Mercer, K., \& Boger, J. (2021). Technologies for fostering intergenerational connectivity and relationships: Scoping review and emergent concepts. Technology in Society, 64, 101494.

Stein, A. (2019). Keeping up with the Joneses on Social Media. Retrieved on 11.03.2020 from: $\mathrm{h}$ ttps://www.rehabs.com/pro-talk/keeping-up-with-the-joneses-of-social-media/

Underwood, R., Bond, E., \& Baer, R. (2001). Building service brands via social identity:

Lessons from the sports marketplace. Journal of Marketing Theory and Practice,

9(1), 1-13.

This is an open-access article published and distributed under the terms and conditions of

the cc) ${ }_{\mathrm{BY}}$ NC Creative Commons Attribution 4.0 International License of United States unless otherwise stated. Access, citation and distribution of this article is allowed with full recognition of the authors and the source. Authors seeking to publish with an Internationally Peer Reviewed Journals should consider https://www.ijcab.org/ by writing to the Editor at editor@ijcab.org or submitting online at https://journals.ijcab.org/journals/index.php. The articles must be quality and meet originality test.

$\frac{\text { IJCAB }}{\text { Publishing Group }}$ 